\title{
Short communication: Effects of feeding purple corn (Zea mays L.) silage on productivity and blood superoxide dismutase concentration in lactating cows
}

\author{
T. Matsuba, ${ }^{1}$ H. Kubozono, ${ }^{1}$ A. Saegusa, ${ }^{1}$ K. Obata, ${ }^{1}$ K. Gotoh,${ }^{2}$ K. Miki, ${ }^{2}$ T. Akiyama, ${ }^{3}$ and M. Oba ${ }^{4 *}$ \\ ${ }^{1}$ Dairy Technology Research Institute, National Federation of Dairy Co-operative Associations (ZEN-RAKU-REN), Fukushima, Japan 969-0223 \\ ${ }^{2}$ Nagano Animal Industry Experiment Station, Nagano, Japan 399-0711 \\ ${ }^{3}$ Takii and Co. Ltd., Kyoto, Japan 600-8686 \\ ${ }^{4}$ Department of Agricultural, Food and Nutritional Science, University of Alberta, Edmonton, Canada T6G 2P5
}

\section{ABSTRACT}

The objective of this study was to evaluate the effects of feeding purple corn (Zea mays L.) silage on productivity and blood superoxide dismutase concentration in lactating cows. We hypothesized that feeding purple corn silage (AX-152; Nagano Animal Industry Experiment Station, Nagano, Japan, and Takii and Co. Ltd., Tokyo, Japan), which is high in anthocyanin content, would increase milk production and blood concentration of superoxide dismutase. We assigned 16 Holstein cows (8 primiparous and 8 multiparous) in mid lactation to 1 of 2 treatments in a randomized block design, with efforts to balance parity, body weight, and days in milk between treatments. Experimental diets contained either purple corn silage [PCS; $31.2 \%$ dry matter (DM), $8.4 \%$ crude protein, $40.2 \%$ neutral detergent fiber, and $26.6 \%$ starch] or conventional corn silage (CONT; $30.5 \%$ dry matter, $8.7 \%$ crude protein, $42.1 \%$ neutral detergent fiber, and $26.5 \%$ starch) at approximately $32 \%$ of diet DM. Both PCS and CONT were ensiled for 5 mo before the study. Treatment diets were fed as total mixed rations ad libitum for $12 \mathrm{wk}$ from February 1 to April 25, 2016. Cows fed the PCS had increased milk yield (31.7 vs. $29.2 \mathrm{~kg} / \mathrm{d}$ ) and blood superoxide dismutase concentrations (9,333 vs. 8,467 $\mathrm{U} / \mathrm{mL}$ ) compared with those fed CONT. However, anthocyanin concentration in the PCS decreased over the 12-wk experiment: $70 \mathrm{mg} / \mathrm{kg}$ of DM for the first $4 \mathrm{wk}$, $20 \mathrm{mg} / \mathrm{kg}$ of DM for the second $4 \mathrm{wk}$, and undetectable for the last $4 \mathrm{wk}$. We did not detect anthocyanins in the CONT group at any time point. Feeding PCS may increase antioxidant capacity and milk production in dairy cows, but anthocyanin in PCS may be degraded during storage.

Key words: anthocyanin, oxidative stress, antioxidant

Received January 22, 2019.

Accepted April 3, 2019.

*Corresponding author: moba@ualberta.ca

\section{Short Communication}

High-producing lactating cows experience oxidative stress caused by active oxygen (Castillo et al., 2006), which often increases with enhanced milk yield (Hirako et al., 2011) and heat stress (Sakatani et al., 2012). Active oxygens are necessary to protect animals from pathogens, but they also damage animal tissues unless they are removed properly; as such, inclusion of antioxidants in dairy diets is necessary. Anthocyanin, a polyphenol derived from plants, has antioxidant activity both in vitro (Tsuda et al., 1994, 1996; Gabrielska et al., 1999) and in vivo (Seeram et al., 2006; Cimino et al., 2007). Hosoda et al. (2012a) reported that feeding an anthocyanin-rich corn silage to sheep increased their plasma antioxidant function, measured by the extent of lipids oxidized by added active oxygens. Purple corn (Zea mays L.) has high concentrations of anthocyanin (Hosoda et al., 2009), and it is expected to reduce oxidative stress in animals; Hosoda et al. (2012b) reported that feeding purple corn silage increased plasma concentrations of superoxide dismutase (SOD) in lactating cows. Although reduced oxidative stress could be expected to contribute to improved animal performance, the effects of feeding purple corn silage on the productivity of lactating dairy cows has not been extensively studied. The objective of our study was to evaluate the effects of feeding purple corn silage on productivity and blood concentration of SOD in lactating cows; we hypothesized that feeding purple corn silage would increase milk production.

Sixteen Holstein cows ( 8 primiparous and 8 multiparous; $\mathrm{BW}: 575 \pm 10.0 \mathrm{~kg}$, mean $\pm \mathrm{SD}$ ) in mid lactation (DIM: $137 \pm 10.4 \mathrm{~d}$ ) were assigned to 1 of 2 experimental diets, with efforts to balance parity, BW, and DIM between treatments. All cows were housed in individual tie stalls at the Dairy Technology and Research Institute of Zen-Raku-Ren (Yabuki, Fukushima, Japan).

Purple corn (Zea mays L.; AX-152) and conventional corn, at approximately $31 \%$ DM content, were chopped 
to a theoretical cutting length of $9 \mathrm{~mm}$ and ensiled in bunker silos $(4.1 \mathrm{~m}$ wide $\times 1.2 \mathrm{~m}$ high $\times 14.9 \mathrm{~m}$ long $)$ with silage inoculants (Cyprolact; Nissan Gosei, Kogyo Co. Ltd., Tokyo, Japan) for 5 mo before the study. Experimental diets, using either purple corn silage (PCS; $31.2 \% \mathrm{DM}, 8.4 \% \mathrm{CP}, 40.2 \% \mathrm{NDF}$, and $26.6 \%$ starch) or conventional corn silage (CONT; 30.5\% DM, 8.7\% CP, $42.1 \% \mathrm{NDF}$, and $26.5 \%$ starch) as the primary forage source, were formulated for similar energy and nutrient content using Cattle.Pro version 4.6 (AMTS, Groton, NY). Dietary concentrations of DM, starch, CP, and NDF were 50.6, 24.0, 15.7, and $33.2 \%$ for the PCS diet, and $49.7,22.6,16.2$, and $34.5 \%$ for the CONT diet, respectively, on a DM basis, except for DM (Table 1). Experimental diets were fed as TMR ad libitum for 12 wk from February 1, 2016, to April 25, 2016. Fresh water was available at all times to all cows. All cows were fed 3 times daily at 0530,1100 , and $1630 \mathrm{~h}$, and milked twice a day at 0600 and $1700 \mathrm{~h}$.

Diet ingredients were sampled weekly, composited to a sample over $4 \mathrm{wk}$, and analyzed at Zen-Raku-Ren Analysis Center (Kamisu, Ibaraki, Japan) for concentrations of DM, ash, CP, ether extract, and starch according to AOAC (1990), and for NDF and ADF according to AOAC International (2002). We measured the anthocyanin (cyanidin 3-glucoside) content of both corn silages using HPLC according to Cassinese et al. (2007). Milk yield was recorded daily throughout the study and averaged weekly. Milk samples were collected weekly from both milkings and analyzed for milk component concentrations using MilkoScan (Foss Electric, Hillerød, Denmark) and for anthocyanin content (Cassinese et al., 2007). Blood was sampled from the coccygeal blood vessel by venipuncture at $1400 \mathrm{~h}$ every 4 wk throughout the study. Blood samples were collected into vacutainers (Venoject II VP-H100K with heparin sodium; Terumo Corp., Tokyo, Japan), and analyzed for SOD concentration using a SOD assay kit (PK-CA577-K335; PromoCell Gmbh, Heidelberg, Germany). We measured DMI for 3 consecutive days every 2 wk and then averaged it. We measured BW and BCS at $1000 \mathrm{~h}$ every $4 \mathrm{wk}$ throughout the study. All data were analyzed using JMP12 (SAS Institute Inc., Cary, $\mathrm{NC}$ ) according to the following model:

$$
\begin{aligned}
\mathrm{Y}_{\mathrm{ijk}}= & \mu+\mathrm{T}_{\mathrm{i}}+\mathrm{P}_{\mathrm{j}}+\mathrm{A}\left(\mathrm{P}_{\mathrm{j}}\right)+\mathrm{TP}_{\mathrm{ij}}+\mathrm{e}_{\mathrm{ij}}+\mathrm{W}_{\mathrm{k}} \\
& +\mathrm{TW}_{\mathrm{ik}}+\mathrm{PW}_{\mathrm{jk}}+\mathrm{TPW}_{\mathrm{ijk}}+\mathrm{e}_{\mathrm{ijk}},
\end{aligned}
$$

where $Y_{\mathrm{ijk}}$ is the dependent variable; $\mu$ is the overall mean; $T_{i}$ is the fixed effect of treatment; $P_{j}$ is the fixed effect of parity; $A\left(P_{j}\right)$ is the random effect of animals nested in parity; $\mathrm{TP}_{\mathrm{ij}}$ is the effect of treatment $\times$ parity interaction; $e_{i j}$ is the residual for treatment and parity
Table 1. Ingredients and analyzed nutrient composition (\% of DM

\begin{tabular}{|c|c|c|}
\hline Item & PCS & CONT \\
\hline \multicolumn{3}{|l|}{ Diet ingredient } \\
\hline Purple corn silage & 33.1 & - \\
\hline Control corn silage & - & 31.3 \\
\hline Klein grass hay & 13.6 & 12.3 \\
\hline Alfalfa hay & 8.1 & 8.6 \\
\hline Beet pulp & 3.5 & 5.6 \\
\hline Dry ground corn & 9.1 & 9.5 \\
\hline Steam flake corn & 6.4 & 6.1 \\
\hline Dry ground sorghum & 1.4 & 1.4 \\
\hline Dry ground wheat & 0.7 & 0.8 \\
\hline Cottonseed & 4.7 & 3.8 \\
\hline Soybean meal & 6.4 & 6.7 \\
\hline Canola meal & 2.1 & 2.2 \\
\hline Heated soybean meal $^{2}$ & 1.4 & 1.6 \\
\hline Corn gluten meal & 0.6 & 0.7 \\
\hline Corn gluten feed & 3.9 & 4.0 \\
\hline Rice bran & 0.1 & 0.1 \\
\hline Molasses & 1.0 & 1.1 \\
\hline Wheat bran & 0.9 & 0.9 \\
\hline Sodium bicarbonate & 0.5 & 0.5 \\
\hline Calcium carbonate & 0.4 & 0.4 \\
\hline Mineral $\mathrm{mix}^{3}$ & 0.6 & 0.6 \\
\hline Vitamin and trace mineral $\mathrm{mix}^{4}$ & 0.4 & 0.4 \\
\hline Fat supplement ${ }^{5}$ & 0.5 & 0.6 \\
\hline Methionine supplement ${ }^{6}$ & 0.06 & 0.08 \\
\hline \multicolumn{3}{|l|}{ Nutrient composition } \\
\hline DM, \% & 50.6 & 49.7 \\
\hline $\mathrm{NE}_{\mathrm{L}}, \mathrm{Mcal} / \mathrm{kg}$ of $\mathrm{DM}$ & 1.58 & 1.57 \\
\hline Starch & 24.0 & 22.6 \\
\hline Sugar & 5.1 & 5.3 \\
\hline NFC & 39.6 & 38.0 \\
\hline $\mathrm{NDF}$ & 33.2 & 34.5 \\
\hline $\mathrm{CP}$ & 15.7 & 16.2 \\
\hline
\end{tabular}
unless otherwise noted) of experimental diets ${ }^{1}$

${ }^{1} \mathrm{PCS}=$ purple corn silage diet; CONT $=$ control corn silage diet. ${ }^{2}$ SoyPlus (West Central Cooperative, IA).

${ }^{3}$ Contained $6 \% \mathrm{Mg}, 26 \% \mathrm{Ca}$, and $13 \% \mathrm{P}$.

${ }^{4}$ Contained $5,000,000 \mathrm{IU} / \mathrm{kg}$ of vitamin $\mathrm{A}, 60,000 \mathrm{IU} / \mathrm{kg}$ of vitamin $\mathrm{D}_{3}$ $22 \mathrm{~g} / \mathrm{kg}$ of D- $\alpha$-tocopherol acetate, $0.3 \mathrm{~g} / \mathrm{kg}$ of thiamine nitrate, $0.1 \mathrm{~g} /$ $\mathrm{kg}$ of riboflavin, $10 \mathrm{~g} / \mathrm{kg}$ of nicotinic acid, $6.7 \mathrm{~g} / \mathrm{kg}$ of D-pantothenate calcium salt, $6 \mathrm{~g} / \mathrm{kg}$ of $\mathrm{Mg}, 0.001 \mathrm{~g} / \mathrm{kg}$ of cyanocobalamin, $10.0 \mathrm{~g} / \mathrm{kg}$ of $\mathrm{Mn}, 0.023 \mathrm{~g} / \mathrm{kg}$ of $\mathrm{Co}, 2.0 \mathrm{~g} / \mathrm{kg}$ of $\mathrm{Cu}, 15.5 \mathrm{~g} / \mathrm{kg}$ of Zn, and 0.126 $\mathrm{g} / \mathrm{kg}$ of I.

${ }^{5}$ NEOFAT-MA (Wawasan Agrolipids Sdn. Bhd., Joho, Malaysia).

${ }^{6}$ Methionine mix containing (\%): 2-hydroxy-4-(metylthio)butanoic acid, $40 ; \mathrm{MgO}, 1.87$.

effects; $W_{k}$ is the fixed effect of week as a repeated measure; $\mathrm{TW}_{\mathrm{ik}}$ is the effect of treatment $\times$ week interaction; $\mathrm{PW}_{\mathrm{jk}}$ is the effect of parity $\times$ week interaction; $\mathrm{TPW}_{\mathrm{ijk}}$ is the effect of treatment $\times$ parity $\times$ week interaction; and $\mathrm{e}_{\mathrm{ijk}}$ is the overall residual. The statistical analysis model for milk production response variables also included pretrial milk yield as a covariate. We used compound symmetry as a covariance structure for repeated measures. Treatment effects were declared significant at $P<0.05$ and tendencies at $0.05 \leq P<0.10$.

The anthocyanin concentration of the PCS diet was $70 \mathrm{mg} / \mathrm{kg}$ of DM for first $4 \mathrm{wk}$ of the study, and $20 \mathrm{mg} /$ $\mathrm{kg}$ of DM for next $4 \mathrm{wk}$ (wk 5 to 8) but was undetect- 


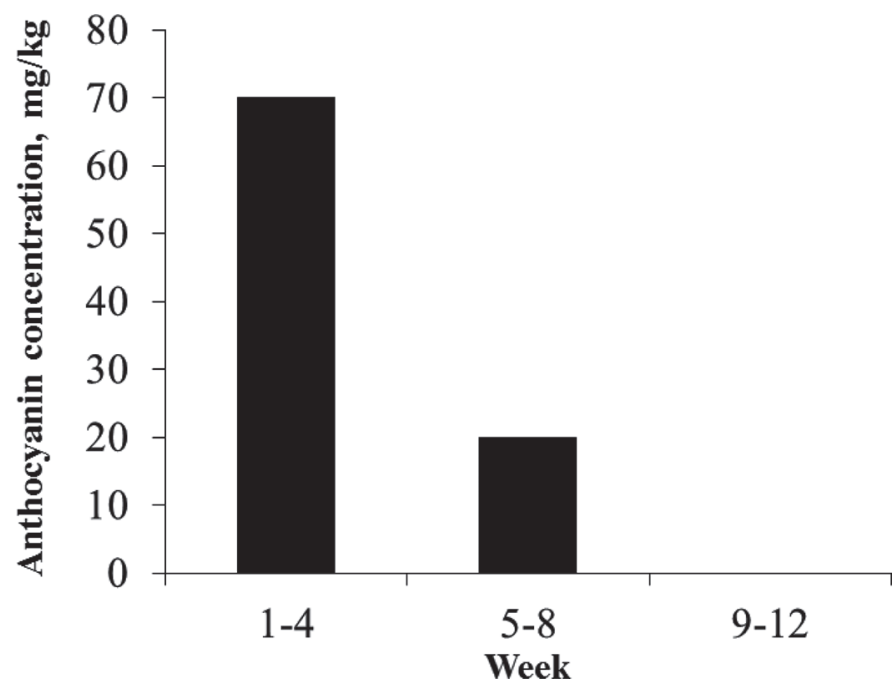

Figure 1. Anthocyanin concentration in purple corn silage during the study. Anthocyanin was not detected in purple corn silage at 9 to $12 \mathrm{wk}$, or in control corn silage throughout the study.

able for the last 4 wk (wk 9 to 12; Figure 1). These values were lower than the anthocyanin concentrations of purple corn silage reported in the literature: $0.34 \%$ of DM (Hosoda et al., 2009) and $862 \mathrm{mg} / \mathrm{kg}$ (Tian et al., 2019). However, our findings agreed with Hosoda et al. (2009), who reported that the anthocyanin content of purple corn silage decreased during storage. We did not detect anthocyanin in the CONT diet throughout the study. We did not measure the anthocyanin content of the purple corn silage before ensiling, so it was not possible to determine the extent of anthocyanin degradation or how quickly it was degraded during the ensiling process or storage. In future studies, it would be warranted to determine the kinetics of anthocyanin degradation during ensiled storage and to investigate factors affecting anthocyanin degradation. This infor- mation would be useful for optimizing the use of purple corn silage, and may help to develop management approaches for slowing anthocyanin degradation in purple corn silage.

Cows fed the PCS diet had higher blood SOD concentrations (9,333 vs. $8,467 \mathrm{U} / \mathrm{mL} ; P<0.01$; Table 2$)$ and increased milk yield (31.7 vs. $29.2 \mathrm{~kg} / \mathrm{d} ; P<0.05)$ compared with cows fed the CONT diet. However, DMI was not affected by treatment, and concentrations of MUN (11.8 vs. $12.9 \mathrm{mg} / \mathrm{dL} ; P<0.05)$ were lower for cows fed the PCS diet than for those fed the CONT diet. The greater milk production observed for cows fed the PCS diet, without increases in DMI, may be at least partly attributed to their greater antioxidant capacity, indicated by enhanced blood SOD concentrations. Although the anthocyanin content of the PCS diet decreased over time, anthocyanin was present in the PCS diet for two-thirds of the experimental period (8 wk). Anthocyanin exhibits antioxidant function in vitro (Tsuda et al., 1994, 1996; Gabrielska et al., 1999) and in vivo (Seeram et al., 2006; Cimino et al., 2007), and Hosoda et al. (2012a,b) reported that antioxidant function and plasma SOD concentration were increased by feeding corn silage containing anthocyanin. Tanaka et al. (2008) have shown that oxidative stress can decrease milk production. Excessive oxidative stress may increase animals' energy expenditure; reducing oxidative stress may contribute to greater efficiency of energy use for milk production, increasing milk production with similar DMI.

We did not detect significant time $\times$ treatment interactions for blood SOD concentration or milk yield, although the anthocyanin content of the PCS diet declined throughout the study. Greater temporal anthocyanin intake may exert prolonged effects on antioxidant capacity. Greater milk production may also be attributed to greater digestibility of the PCS diet.

Table 2. Effects of purple corn silage on DMI, milk production, and blood superoxide dismutase (SOD) in lactating dairy cows $^{1}$

\begin{tabular}{lcccc}
\hline Item & PCS & CONT & SEM & $P$-value \\
\hline DMI, kg/d & 22.2 & 21.5 & 0.80 & 0.38 \\
BW, kg & 605 & 609 & 8.2 & 0.69 \\
BCS & 2.93 & 3.01 & 0.03 & 0.05 \\
Milk yield and composition & & & & \\
Milk yield, kg/d & 31.7 & 29.2 & 0.68 & $<0.05$ \\
$4 \%$ FCM, kg/d & 32.3 & 30.3 & 0.71 & 0.06 \\
Milk fat, kg/d & 1.31 & 1.24 & 0.04 & 0.25 \\
Milk protein, kg/d & 1.05 & 0.99 & 0.02 & 0.14 \\
Lactose, kg/d & 1.45 & 1.33 & 0.04 & 0.06 \\
Milk fat, \% & 4.14 & 4.30 & 0.15 & 0.50 \\
Milk protein, \% & 3.33 & 3.43 & 0.09 & 0.47 \\
Lactose, \% & 4.59 & 4.57 & 0.04 & 0.74 \\
MUN, mg/dL & 11.8 & 12.9 & 0.29 & $<0.05$ \\
Blood SOD, U/mL & 9,333 & 8,467 & 281 & $<0.01$ \\
\hline
\end{tabular}

${ }^{1} \mathrm{PCS}=$ purple corn silage diet; CONT $=$ control corn silage diet. 
Although we did not measure total-tract or ruminal nutrient digestibility, Sawai (2012) reported that the in vitro DM degradability of purple corn stover was higher, and attributed it to enhanced endogenous antioxidative activity. It should also be noted that the dietary starch content was slightly higher for the PCS diet than the CONT diet in the current study, and this may also have contributed to greater milk production for the cows fed the PCS diet.

This preliminary study suggested that feeding purple corn silage, which contains anthocyanin, may increase blood SOD concentration and milk production in dairy cows, but that the anthocyanin in purple corn silage may be degraded over time during storage in silo. Further research is warranted to evaluate the effects of feeding purple corn silage on antioxidant capacity and nutrient digestibility in lactating dairy cows. The extent and kinetics of anthocyanin degradation in purple corn silage during ensiled storage also need to be evaluated.

\section{ACKNOWLEDGMENTS}

This work was supported by Nagano Animal Industry Experiment Station (Nagano, Japan) and Takii and Co. Ltd. (Kyoto, Japan).

\section{REFERENCES}

AOAC. 1990. Official Methods of Analysis. 15th ed. Assoc. Off. Anal Chem., Gaithersburg, MD.

AOAC International. 2002. Official Methods of Analysis. 17th ed. AOAC International, Gaithersburg, MD.

Cassinese, C., E. D. Combarieu, M. Falzoni, N. Fuzzati, R. Pace, and N. Sardone. 2007. New liquid chromatography method with ultraviolet detection for analysis of anthocyanins and anthocyanidins in Vaccinium myrtillus fruit dry extracts and commercial preparations. J. AOAC Int. 90:911-919.

Castillo, C., J. Hernandez, I. Valverde, V. Pereira, J. Sotillo, M. L. Alonso, and J. L. Benedito. 2006. Plasma malonaldehyde (MDA) and total antioxidant status (TAS) during lactation in dairy cows. Res. Vet. Sci. 80:133-139.
Cimino, F., V. Sulfaro, D. Trombetta, A. Saija, and A. Tomaino. 2007. Radical-scavenging capacity of several Italian red wines. Food Chem. 103:75-81.

Gabrielska, J., J. Oszmianski, M. Komorowska, and M. Langner. 1999. Anthocyanin extracts with antioxidant and radical scavenging effect. Z. Naturforsch. C 54:319-324.

Hirako, M., H. Takahashi, and S. Kushibiki. 2011. Current situation of fertility decline in dairy cattle and its relation to the uterine environment. J. Japan. Soc. Clin. Infect. Dis. Farm Anim. 6:123-130.

Hosoda, K., B. Eruden, H. Matsuyama, and S. Shioya. 2009. Silage fermentative quality and characteristics of anthocyanin stability in anthocyanin-rich corn (Zea mays L.). J. Anim. Sci. 22:528-533.

Hosoda, K., M. Matsuo, M. Miyaji, H. Matsuyama, H. Maeda, H. Ohta, H. Kato, and K. Nonaka. 2012b. Fermentative quality of purple rice (Oryza sativa L.) silage and its effects on digestibility, ruminal fermentation and oxidative status markers in sleep: A preliminary study. Grassl. Sci. 58:161-169.

Hosoda, K., M. Miyaji, H. Matsuyama, S. Haga, H. Ishizaki, and K. Nonaka. 2012a. Effect of supplementation of purple pigment from anthocyanin-rich corn (Zea mays L.) on blood antioxidant activity and oxidation resistance in sheep. Livest. Sci. 145:266-270.

Sakatani, M., A. Z. Balboula, K. Yamanaka, and M. Takahashi. 2012. Effect of summer heat environment on body temperature, estrous cycles and blood antioxidant levels in Japanese Black cow. J. Anim. Sci. 83:394-402.

Sawai, A. 2012. Endogenous antioxidative activity increases dry-matter degradability in purple maize (Zea mays L.) stover. J. Warm Regional Soc. Anim. Sci. Jap. 55:135-141.

Seeram, N. P., R. Lee, H. S. Scheuller, and D. Heber. 2006. Identification of phenolic compounds in strawberries by liquid chromatography electrospray ionization mass spectroscopy. Food Chem. 97:1-11.

Tanaka, M., Y. Kamiya, T. Suzuki, M. Kamiya, and Y. Nakai. 2008. Relationship between milk production and plasma concentrations of oxidative stress markers during hot season in primiparous cows. Anim. Sci. J. 79:481-486.

Tian, X. Z., P. Paengkoum, S. Paengkoum, S. Chumpawadee, C. Ban, and S. Thongpea. 2019. Short communication: Purple corn (Zea mays L.) stover silage with abundant anthocyanins transferring anthocyanin composition to the milk and increasing antioxidant status of lactating dairy goats. J. Dairy Sci. 102:413-418.

Tsuda, T., K. Shiga, K. Ohsima, S. Kawasaki, and T. Osawa. 1996. Inhibition of lipid peroxidation and the active oxygen radical scavenging effect of anthocyanin pigments isolated from Phaseolus uulgaris L. Biochem. Pharmacol. 52:1033-1039.

Tsuda, T., M. Watanabe, K. Ohshima, S. Norinobu, S. W. Choi, S. Kawakishi, and T. Osawa. 1994. Antioxidative activity of the anthocyanin pigments cyanidin 3 -O- $\beta$-D-glucoside and cyanidin. J. Agric. Food Chem. 42:2407-2410. 